\title{
CORPOS VELHOS (RE)CONFIGURADOS ${ }^{1}$
}

\section{OLD BODIES (RE)CONFIGURED}

\author{
Gabriela Felten da Maia²
}

\section{RESUMO}

A recente 'descoberta' da velhice como uma entidade demográfica e sua ascensão ao status de problema social modificou o quadro dos estudos do envelhecimento no Brasil, constituindo a velhice em um objeto de intervenção e investigação científica. Assistimos a um número cada vez maior de especialistas que buscam construir critérios que definam o que é envelhecimento e quando alguém pode ser considerado velho, em um processo dinâmico de interlocução entre discursos biológicos, políticos, sociais, econômicos e psicológicos, que produzem categorias capazes de reconhecer determinados sujeitos como pertencentes ou não à categoria velho. No presente artigo, procura-se, sob a perspectiva sócio-antropológica, chamar a atenção para os contextos culturais e sociais em que emergem os significados sobre envelhecimento, os quais configuram e posicionam os sujeitos em diferentes lugares sociais. Procurando destacar que a velhice não é uma condição estática do corpo, mas um processo por meio do qual se materializam corpos velhos, problematiza-se a nomeação de diferenças que definem quem é velho ou não. Deste modo, é necessário refletir sobre a constituição de um conjunto de discursos e práticas que tornou possível reconhecer determinados sujeitos como pertencentes a determinadas categorias e como estes são tomados como definidores de sujeitos e suas possibilidades.

Palavras-chave: Velhice. Corpos. Processos de subjetivação. Produção de saberes. Gerontologia.

\footnotetext{
1 Trata-se de um recorte da discussão realizada na dissertação de mestrado defendida no Programa de PósGraduação em Ciências Sociais da UFSM. Esta pesquisa contou com o apoio da Coordenação de Aperfeiçoamento de Pessoal de Nível Superior, CAPES.

2 Psicóloga, Mestre em Ciências Sociais, e-mail para contato: gabryelamaia@gmail.com.
} 


\section{ABSTRACT}

The recent 'discovery' of old age as a demographic entity and its ascension to the status of social problem has changed the context of studies of aging in Brazil, representing the old age in an object of intervention and research. We witness a growing number of experts who seek to construct criteria that define what is aging and when someone may be considered an old person in a dynamic process of interaction between biological, political, social, economic and psychological discourses, which can produce categories to recognize certain individuals as belonging or not to old category. This paper attempts, under the socio-anthropological perspective, to draw attention to the cultural and social contexts in which meanings of aging emerge, which the subjects are shaped and positioned in different social positions. Searching to point that aging is not a static condition of the body, but a process through which bodies are materialized as old, we problematize the appointment of differences that define who is old or not. Thus, it is necessary to reflect the constitution of a set of discourses and practices that made it possible to recognize certain individuals as belonging to certain categories and how these are taken as defining of subjects and its possibilities.

Keywords: Aging. Bodies. Processes of subjectivation. Knowledge production. Gerontology.

\section{PARA ABRIR O DEBATE}

Um velho ${ }^{3}$, de 83 anos, que aqui será chamado de P. ${ }^{4}$, ao ser interpelado a respeito da velhice, apresentou duas categorias - Novo-velho, velho-novo - que ouvira de um locutor de rádio, quando este explicava em seu programa as diferentes formas de encarar o envelhecimento na atualidade. Ao introduzir tais categorias, P. salientou algo muito importante: que em sua época de juventude e maioridade temas como doenças na velhice e receitas de cuidados com a saúde, para se chegar a uma velhice bem-sucedida, não eram discutidos. Pode-se pensar em duas proposições para essa questão:

1) A juventude de P. foi na década de 50 , momento em que, como atestam alguns estudos demográficos, o perfil epidemiológico começava a dar sinais de mudança. Neste período, conforme os dados do IBGE (2007), o Brasil caracterizava-se por uma configuração etária com traços de uma população predominantemente jovem. Contudo, a partir da década de 40 , há sinais de mudanças na configuração etária do país, em razão de diversos fatores, culminando no aumento da longevidade e no envelhecimento populacional. Este fato, apesar de não poder ser considerado como a justificativa para a menor visibilidade do envelhecimento, neste período, explica em parte a pouca atenção, já destacada por P., em relação às doenças hoje associadas ao envelhecimento.

2) Dado que há um aumento populacional de velhos no Brasil, os problemas que os acompanham têm suscitado a elevada atenção de formuladores de políticas sociais para as demandas específicas deste contingente. Tal fato, em boa medida, têm justificado a produção de

\footnotetext{
3 Optou-se pela utilização da palavra 'velho' por engajar-se nas discussões próprias do campo de estudos sobre a velhice e o envelhecimento. Sobre essas reflexões ver Clarice Peixoto (2000) e Guita Grin Debert (2004).

4 Devido a questões relacionadas à ética de pesquisa, o nome do participante aqui citado será preservado no anonimato, sendo seus comentários referenciados através de uma letra do alfabeto. Vale destacar que a inclusão desses comentários visa apenas a introduzir o debate proposto neste artigo.
} 
conjuntos de ações e discursos que objetivam promover um envelhecimento saudável e, consequentemente, que exigem uma mudança de sensibilidade com relação à velhice, tal como se pode acompanhar em algumas discussões ${ }^{5}$.

Essas questões têm sido tratadas como justificativa, em boa medida, para a atenção voltada à população de mais idade, para a crescente quantidade de produções que buscam discutir a questão do envelhecimento no Brasil, bem como para o reflorescimento da geriatria, haja vista que o aumento populacional alterou o perfil do debate em torno das políticas sociais e a velhice ganhou o status de problema social. A recente 'descoberta' da velhice como uma entidade demográfica modificou o quadro dos estudos sobre o envelhecimento no Brasil na medida em que os novos discursos juntaram-se ao da geriatria, fazendo da velhice, portanto, um objeto de intervenção.

\section{PRODUÇÃO DE "SABERES E VERDADES" SOBRE A VELHICE}

A partir de estudos antropológicos é possível compreender que há distintas formas de envelhecer em diferentes culturas. Sob este ponto de vista, a compreensão de que o envelhecimento é uma condição biológica à qual o indivíduo submete-se passivamente não pode mais ser admitida, visto que a velhice é um fenômeno tanto biológico quanto social/cultural e suas reações acontecem com base em seus pertencimentos. O envelhecimento é vivido e percebido diferentemente em cada sociedade, grupo e geração, conforme as distintas particularidades culturais, sociais e econômicas, particularidades estas que permitem aos indivíduos de um grupo interpretar a própria experiência e guiar suas ações (ARCAND, 1982; UCHÔA, FIRMO \& LIMACOSTA, 2002).

Os estudos demonstram que a cultura está presente na constituição da percepção sobre o envelhecimento, o que permite considerar que $a$ velhice em si mesma não tem significado algum. Pelo contrário, sua realidade biológica em si nada diz sobre ela, adquirindo sentido apenas na medida em que outros atribuem significado ao processo. Velhice, nesse caso, não constitui uma propriedade substancial que o indivíduo adquire ao longo da vida, e sim uma construção de diferentes práticas e representações historicamente produzidas que fazem ver e falar certos modos de sentir, pensar e agir (ARCAND, 1982; MINAYO \& COIMBRA JR., 2002; BARROS \& CASTRO, 2002).

Considerando esta perspectiva, é possível esboçarmos a problemática deste trabalho: quando se fala de velhice, do que se está falando? Que imagens surgem ao fazer operar certos modos de ver o envelhecimento? A quem interessa tais imagens? E o que elas implicam? Estas perguntas surgem em meio a um debate que gera opiniões controversas dentro da gerontologia, dada a existência de visões conflitantes sobre o envelhecimento e coexistentes nas leituras sobre tal processo.

As discussões vão desde uma visão do declínio da vida pública e da tirania da intimidade - como sugere Sennett (1988), que produz uma espécie de estetização da vida, em que envelhecer passa a ser visto como uma questão de escolha individual, passível de manipulação pelo próprio sujeito - até aquilo que Giddens (1991) chamou de caráter reflexivo da modernidade, em que, à luz da constante entrada de conhecimentos, estes, ao serem examinados, podem vir a afetar as ações dos indivíduos ou grupos. Tais debates podem apresentar a experiência de enve-

\footnotetext{
5 Ver sobre I Assembléia Mundial sobre o Envelhecimento, ocorrida em 1982, e II Assembléia Mundial sobre o Envelhecimento, ocorrida 2002, nas quais são apresentados um Plano Internacional de Ação para o Envelhecimento. Além disso, ver também: (1) Renato Veras (2001); (2) Ana Amélia Camarano (2004); (3) Laura Lídia Rodríguez Wong \& José Alberto Magno de Carvalho (2006); e (4) Maria das Graças Melo Fernandes \& Sérgio Ribeiro dos Santos (2007).
} 
Ihecer como boa ou ruim, ativa ou inativa, de modo que ora essas experiências são vistas negativamente, ora positivamente, conforme os aspectos aos quais se dá ênfase. Como apresentam Minayo \& Coimbra Jr. (2002), tais aspectos abrangem tanto a noção de um problema social quanto a mudança que esse grupo crescente em número provoca ao ressignificar o seu lugar tradicionalmente percebido como de "peso social" e inatividade.

São modos de ver que se constituem num processo dinâmico de interlocução entre os discursos biológico, médico, psicológico, econômico e político. Esses discursos são produzidos por diferentes agentes sobre o envelhecimento e formam uma categoria capaz de reconhecer determinados sujeitos como pertencentes a um grupo delimitado, que é ele mesmo préconstruído.

Portanto, a construção do objeto, de que fala Bourdieu (1998), adquire importância para este trabalho na medida em que a sociedade elabora um conjunto de problemas relativos a uma determinada população e transforma-os em problemas socialmente relevantes, o que justifica, equivocadamente para alguns pesquisadores, a construção dos mesmos como objetos científicos. Contudo, a importância social, política ou econômica de uma população $x$ não pode ser considerada suficiente para orientar as escolhas de um objeto de estudo. É necessário que seja feita a história social da emergência e constituição de determinados temas como objeto de preocupações sociais e do trabalho coletivo, que permitem o reconhecimento de determinados problemas como legítimos de análise.

Nesse sentido, não se pode desconsiderar que o discurso gerontológico, no processo de construção de seu objeto, age de forma a legitimar seu campo de saber, transformando o envelhecimento em um "problema social" digno de ser discutido, haja vista que se pauta em alguns discursos recorrentes: 1) dados demográficos que indicam o crescimento significativo de velhos no total da população; e 2) que, associados às demandas específicas dos idosos, conduzem à reavaliação sobre os gastos públicos e à intensificação de discussões em torno da influência negativa que o aumento da população de velhos acarreta(rá) ao sistema previdenciário e ao setor de saúde pública.

Essa recorrente referência à mudança demográfica que está ocorrendo na sociedade brasileira ${ }^{6}$ e suas possíveis consequências tem justificado a crescente produção de conhecimento sobre a velhice, principalmente em relação à problemática epidemiológica e ao desenvolvimento de políticas públicas para atender às demandas de um contingente cada vez mais significativo numericamente. Embora tais estudos destaquem uma questão importante que poderá afetar a sociedade no tocante à assistência a esta população, Debert (2004) propõe que seja problematizada a atuação desses discursos no processo de "reinvenção da velhice" para que se observe a emergência de um novo velho, expressão de certos modos de existir e alvo de investigação científica.

Logo, a mudança que marca o envelhecimento na atualidade incita que sejam tecidas algumas considerações sobre a constituição de um conjunto de discursos e práticas que tornou possível reconhecer determinados sujeitos como pertencentes a uma determinada categoria.

\footnotetext{
6 Em 1940, a distribuição percentual de jovens entre 0 e 14 anos correspondia a 42,9\%, contra 4,1\% com mais de 60 anos. No censo demográfico de 2000, a contribuição da população entre 0 e 14 anos diminuiu para $29,6 \%$, enquanto o grupo com mais de 60 anos aumentou para $8,6 \%$. Este processo demonstra a progressiva redução da participação relativa de crianças e jovens bem como o consequente aumento de estruturas etárias envelhecidas no total da população do país, conforme dados do IBGE (2007). Estima-se que em 2020 o contingente de pessoas com mais de 60 anos poderá ultrapassar 30 milhões, passando a represen$\operatorname{tar} 13 \%$ da população.
} 


\section{VELHICE, DO QUE SE ESTÁ FALANDO?}

Quando uma pessoa torna-se velha? Que critérios definem essa categorização? Uma pessoa é tão velha quanto o seu corpo determina? Essas são perguntas que, de modo geral, permeiam algumas discussões dentro do campo gerontológico no que tange à constituição de seu objeto - a velhice. Para Groisman (2002), estas são questões difíceis de responder dada a inexistência de uma conceituação clara do que venha a ser envelhecer para a gerontologia. Ademais, esta espécie de 'frouxidão conceitual' (SÁ, 1999) provoca questionamentos quanto à existência de uma metodologia e de uma teoria próprias para o campo gerontológico, que possam delimitar claramente critérios definidores do que é o envelhecimento.

$\mathrm{Na}$ busca de uma delimitação clara, esta disciplina direcionou-se para o corpo e seus processos bio-fisiológicos como forma de encontrar os critérios válidos que pudessem demarcar o que é, afinal, a velhice e quando se inicia o envelhecimento. Do ponto de vista biológico, o envelhecimento é descrito em relação à degeneração do organismo, com o passar do tempo. Haveria, neste modo de entender, a premissa de que o tempo é uma variável importante para a análise de tal processo. Contudo, como aponta Groisman (2002), o maior problema está na validade do uso de tal variável para medir quando a degeneração se inicia ou o exato grau de degeneração do corpo. A idade cronológica, nesse sentido, não pode ser considerada critério definidor do envelhecimento, justamente em função da sua relação com o ambiente.

A questão basilar no estudo do envelhecimento, para Jeckel-Neto (2001), é saber o que acontece com as variáveis biológicas à medida que o tempo passa. Se estas não são atemporais, isso significa que as modificações que ocorrem no ambiente em que os indivíduos estão expostos, ao longo do tempo, interagem com os fatores biológicos, promovendo alterações no processo de envelhecimento. Conclui-se, então, que nem a idade e nem o envelhecimento são definitivamente observáveis; na realidade, são estimativas baseadas no conjunto de consequências causadas no organismo, com o passar do tempo.

Como salienta o autor acima citado, o envelhecimento deve ser pensado como multifatorial, envolvendo diferentes níveis do organismo, desde o molecular ao fisiológico e morfológico, além de componentes sociais, culturais e psicológicos. A complexidade desse processo mina os esforços de consolidar critérios válidos e fidedignos para se medir exatamente o grau de envelhecimento de uma pessoa. Tal complexidade se explica, de acordo com Groisman (2002), porque o organismo de um indivíduo envelhece de modo não homogêneo entre os seus tecidos, ossos, órgãos, nervos e células, podendo um grupo de pessoas da mesma idade cronológica estar em estágios distintos de envelhecimento, o que, entre outras coisas, justifica a heterogeneidade de formas de se vivenciar este processo.

Mas, de modo geral, as dificuldades encontradas na gerontologia derivam de uma contradição no que concerne ao entendimento de velhice: seria esta um estado normal ou patológico? Como estabelecer normas que determinem o que seria saudável na velhice? E, por fim, a partir de quais critérios pode-se determinar o que venha a ser envelhecimento normal ou patológico e o envelhecimento bem-sucedido?

A dificuldade em criar normas orgânicas para determinar o que seja envelhecimento impulsiona o surgimento de um aparato artificialmente normalizador, no qual fatores sociais e culturais, combinados com características fisiológicas e morfológicas, influenciam na atribuição de significado à velhice. Nesse sentido, podemos considerar uma pessoa tão velha quanto o seu cérebro, ou pela determinação de seu programa genético, ou pelo seu estado de espírito, ou sua situação civil? O que parece haver é um direcionamento da gerontologia para a identificação de características corporais específicas que diferenciem o corpo envelhecido como um processo de 
natureza fisiológica e celular singular das demais faixas etárias (GROISMAN, 2002), de modo a reconhecer um grupo de pessoas sob uma denominada categoria - os velhos - em que se encontram sinais de degeneração.

Essa dificuldade, apontada por Groisman, em delimitar as fronteiras da ciência do enveIhecimento não diminui o poder que áreas como a gerontologia têm sobre a determinação dos modos de ser velho e de se ver a velhice. Ainda que o saber nesse campo não possua poder pelo seu rigor científico, o mesmo não ocorre em relação ao discurso dos experts (BARROS \& CASTRO, 2002). Conforme Groisman (2002), os problemas internos da gerontologia não parecem ameaçar sua capacidade de se legitimar enquanto campo de saber e intervenção sobre a velhice. $\mathrm{Na}$ realidade, o discurso dos experts é, como salienta Debert (2004), um ativo produtor de formas de gestão da velhice na atualidade, ou seja, é um ativo produtor de modos de ver e viver a velhice na sociedade contemporânea.

Na visão de Debert (2004), Lima (1999) e Barros e Castro (2002), o surgimento de um conjunto de práticas e saberes sobre a velhice faz vincular qualidade de vida a certas práticas de cuidado, produzindo um novo ethos para esta etapa a partir da disseminação de bens e serviços produzidos e identificados para um determinado grupo de pessoas, denominado terceira idade. Em que pese a importância dessa transformação na sensibilidade com relação à velhice, ao serem dissolvidas imagens tradicionais de improdutividade e incapacidade, não se pode esquecer que dar ênfase à velhice como um estilo de vida também é produzir novas categorizações a certos modos de existir que orientam modos de perceber e produzir saber. Nesse sentido, o conceito de envelhecimento bem-sucedido ${ }^{7}$ associa-se a estas práticas e acaba por contribuir para a disseminação de imagens que oscilam entre o bom e o mal envelhecer ao configurarem modos de gestão da velhice que conduzem a uma re-privatização da mesma, ou seja, a uma responsabilização do sujeito sobre o seu próprio envelhecimento.

\section{PRODUZINDO CORPOS-VELHOS}

O Globo Repórter ${ }^{8}$, em 2009, exibiu um especial sobre longevidade com diferentes reportagens sobre a velhice e os cuidados para se viver bem esta etapa da vida. No conjunto das reportagens deste especial, as imagens apresentam uma velhice ativa que se contrapõe ao mal envelhecer. Cuidar a alimentação, manter-se ativo, participar de atividades físicas e grupos de convivência e controlar fatores de risco são algumas das receitas sugeridas para se envelhecer com qualidade. A velhice, nas palavras de Renato Maia, presidente da Associação Internacional de Gerontologia e Geriatria, entrevistado pelo Globo Repórter, "não é uma sala que se abre aos 65 ou 70 anos, é algo que se constrói no dia a dia. Quem fizer uma boa construção agora, seguramente vai ter um envelhecimento, uma velhice mais saudável".

\footnotetext{
7 Envelhecimento bem-sucedido tem sido visto como mais do que ausência de doença e vai além da manutenção das capacidades funcionais, pois outros fatores associam-se à avaliação (MORAES \& SOUZA, 2005). Contudo, em boa medida, vê-se que se mantém, ainda que implicitamente, a oposição normal $X$ patológico, discutida por Groisman (2002), quando se trata de estudos que avaliam a qualidade de vida e os fatores associados ao envelhecimento bem-sucedido, pois a tal oposição se acrescentam apenas outros fatores que se relacionam à saúde dos velhos sem serem problematizados os próprios modelos de classificação e categorização de envelhecimento.

8 Programa produzido pela emissora REDE GLOBO e exibido no dia 03 de abril de 2009, com o título: OS SEGREDOS DA LONGEVIDADE. Disponível no site da Rede Globo: http://g1.globo.com/globoreporter.

9 Ver, por exemplo, entrevista com Mehmet Oz para a Revista Veja, edição de 5 de setembro de 2007 - A mágica do Dr. Oz - "Para aumentar a expectativa de vida, não basta evitar doenças. É preciso exercitar o corpo para que ele não enfraqueça"; e matéria na Folha de São Paulo do dia 08 de setembro de 2010, Envelhecimento é doença controlável.
} 
A entrevista encaminha-se, como boa parte das discussões apresentadas sobre a longevidade, para um receituário por meio do qual é possível alcançar uma velhice bem-sucedida. As implicações desta forma de abordagem do envelhecimento vão ao encontro da crítica de Debert (2004) sobre os discursos da terceira idade, quando estes apontam ou sugerem comportamentos e técnicas de cuidados que começam muito antes de se chegar à velhice propriamente. $O$ objetivo é combater o progresso do envelhecimento e demonstrar que se pode alcançar a velhice sem ficar velho: "aos 70 anos parece uma jovem", "ela tem uma disposição de criança" (falas do repórter).

O conjunto de reportagens apresentado pelo Globo Repórter, ao mostrar que o envelhecimento saudável é possível, dá sinais da centralidade que o corpo adquire no conhecimento da velhice. É através do conhecimento dos mecanismos fisiológicos por que passa o corpo que envelhece que foi possível distinguir o processo de envelhecimento de outros estados de alteração fisiológica. O discurso médico tem papel especial nesse modo de compreensão da longevidade ao construir modelos de envelhecimento saudável a partir de uma gestão da biomedicina e do saber geriátrico/gerontológico sobre o corpo envelhecido.

Ao voltar seu olhar para a superfície do corpo, o saber médico torna possível constituir um discurso sobre a senescência ao investir no corpo envelhecido, reconhecendo os sinais que o atestam como um estado patológico qualitativamente distinto. $\mathrm{O}$ avanço da idade seria associado não apenas "com um enfraque-cimento ou declínio geral, mas com condições corporais específicas, inspirando o desenvolvimento de um conhecimento medicalizado, baseado na idade" (GROISMAN, 2002, p. 70). O corpo envelhecido, deste modo, seria um corpo em processo de morte, já que apresentaria deterioração dos tecidos.

Contudo, se para o campo médico um conhecimento objetivo sobre o corpo permitiria a montagem de seu modelo de intervenção, para o saber sobre a senescência este conhecimento trouxe impasses à intervenção naquilo que era considerado patológico no corpo envelhecido. Como as doenças, o envelhecimento causaria danos ao corpo, porém o modo de ver a senescência como um estado que causaria alterações fisiológicas irreparáveis tornou o próprio envelhecimento uma doença, o que elimina a noção de um envelhecimento saudável. O limite tênue entre velhice e doença dificulta a delineação de uma fronteira entre o estado normal e patológico na velhice, além de, consequentemente, um estabelecimento de padrões de saúde claramente mensuráveis para os velhos, haja vista que o curso normal do processo de envelhecimento geraria modificações patológicas progressivas e incuráveis, levando os indivíduos naturalmente à morte (GROISMAN, 2002).

O aumento populacional de velhos tornou mais urgente, pelo menos no Brasil, que modelos clínicos de intervenção fossem criados para atender à demanda crescente de saúde. No entanto, dada a dificuldade de delimitar critérios que definam quando uma pessoa fica velha bem como a falta de clareza quanto ao que seja normal ou patológico na velhice, uma mudança de olhar se fez necessária na tentativa de desfazer a associação entre velhice e doença. A saúde assume o foco central desse novo olhar, pois agora não se trata mais de pensar o envelhecimento como um processo patológico progressivo e irreversível, e sim de superar as dificuldades impostas por este processo ${ }^{9}$.

Contudo, parece existir um estranho paradoxo nesse novo discurso sobre a velhice: ao mesmo tempo em que se quer rever a noção de velhice como doença, prolifera mais e mais a sua visão patológica, na medida em que surge a noção de velhice saudável. Trata-se de uma intensa produção discursiva que não apenas inverte ou substitui termos, mas que materializa corpos a partir da produção simultânea de domínios inabitáveis. 
A noção de velhice saudável constituída por uma linguagem médico-moral não substitui, então, a sua visão patológica, ao contrário, a produz como um exterior necessário que está, na realidade, "dentro", isto é, compondo aqueles corpos como seu próprio fundante. A percepção de que velho é sempre o outro, na realidade, pode ser pensada como um outro que faz parte de mim, pois a formação de sujeitos, a partir da perspectiva de Judith Butler (BUTLER, 2001; PRINS \& MEIJER, 2002), exige a identificação com a abjeção, através de sua negação.

Para Butler (2001), o sujeito é constituído através da negação a certas identificações cuja existência produz um exterior que demarca, circula e diferencia os sujeitos. Assim, pode-se pensar que a total ou parcial supressão do termo velho, em função das significações negativas que ele assume em determinadas produções na mídia, por gerontólogos, sujeitos envelhecentes, entre outros, não apaga o sujeito (apesar de possuir um efeito de apagamento), visto que a existência do termo e sua constante reiteração são necessárias para circunscrever o domínio dos sujeitos viáveis. Isso significa que a velhice bem-sucedida é circunscrita por certos tipos de corpos que habitam zonas inóspitas da vida social, sendo este habitar necessário para que corpos velhos saudáveis se materializem bem como para que sejam constituídos os limites possíveis à vivência do envelhecimento.

\section{CONSIDERAÇÕES FINAIS}

A discussão realizada nesse artigo tentou pontuar que, apesar da materialidade do enveIhecimento, $a$ velhice não é simplesmente uma condição estática de um corpo. Ainda que se queira buscar o envelhecimento em sua dimensão puramente biológica, este domínio não pode ser separado de contextos histórico-sociais que produzem certos modos de ver e pensar capazes de reconhecer determinados sujeitos como pertencentes ou não à categoria velho.

São os marcadores sociais que orientam o olhar sobre o processo de envelhecimento, determinando o bom e o mal envelhecer, os limites entre o normal e o patológico na velhice, sendo o corpo o definidor do que é ou não velho e do que é ou não é saudável (MOTTA, 2002). A representação do corpo envelhecido em oposição à capacidade para produzir ou de reproduzir deixa clara a presença de um paradigma da juventude que deixou de representar uma fase do curso da vida para tornar-se um estilo de vida que deve ser perseguido por todos.

As manifestações corpóreas, assim, tornam-se perdas em relação ao predomínio de um paradigma da juventude que tem como premissa escapar do envelhecimento. O que parece haver é uma substancialização da juventude como marcador da velhice, uma espécie de determinismo bio-ideológico que a faz ser vista como uma dimensão não-produtiva e terminal da natureza, ou seja, ela não reproduziria a sociedade (MOTTA, 2002).

Assim, $a$ velhice, enquanto categoria definidora, trata-se de uma realidade forjada no entrecruzamento de diferentes vetores que fazem apreendê-la enquanto certos modos de existir que configuram e posicionam os sujeitos em diferentes lugares sociais. Percebe-se que 0 problema não é a velhice em si, mas a forma como a sociedade lida com o corpo e com as questões relacionadas ao envelhecimento, de modo a tornar viáveis determinados corpos em detrimento de outros. 


\section{REFERÊNCIAS BIBLIOGRÁFICAS}

ARCAND, B. La construction culturelle de la vieillesse. Anthropologie et sociétés, Département d’anthropologie, Université Laval, v. 6, n. 3, p. 7-23, 1982. Disponível: <http://classiques.uqac.ca/contemporains/\#cont_a>. Acesso em: 03 mar. 2009.

BARROS, R. D. B.; CASTRO, A. M. Terceira Idade: o discurso dos experts e a produção do "novo velho". Estudos interdisciplinares e envelhecimento, Porto Alegre, v. 4, p. 113-124, 2002.

BOURDIEU, P. Introdução a uma sociologia reflexiva. In: O poder simbólico. 2. ed. Rio de Janeiro: Bertrand Brasil, 1998.

BUTLER, J. Corpos que pesam: sobre os limites discursivos do "sexo". In: LOURO, G. L. (org.). O corpo educado: pedagogias da sexualidade. Belo Horizonte: Autêntica, 2001.

CAMARANO, A. A. (org.). Os novos idosos brasileiros: muito além dos 60? Rio de Janeiro: Ipea, 2004.

DEBERT, G. G. A Reinvenção da Velhice: Socialização e Processos de Reprivatização do Envelhecimento. São Paulo: Universidade de São Paulo, FAPESP, 2004.

FERNANDES, M. G. M.; SANTOS, S. R. Políticas públicas e direitos do idoso: desafios da agenda social do Brasil contemporâneo. In: Achegas.net - Revista de ciência política. Revista eletrônica. Rio de Janeiro, 2007. Disponível em: <http://www.achegas.net/> Acesso em: 14 set. 2007.

GIDDENS, A. As conseqüências da modernidade. São Paulo: UNESP, 1991.

GROISMAN, D. A velhice entre o normal e o patológico. História, Ciências, Saúde, Rio de Janeiro, v. 9, n. 1, p. 6178, 2002.

INSTITUTO BRASILEIRO DE GEOGRAFIA E ESTATÍSTICA. Tendências demográficas: uma análise da população com base nos resultados dos Censos Demográficos 1940 e 2000. Rio de Janeiro, 2007. Disponível em <http:/ /www.ibge.gov.br/>. Acesso em: 07 ago. 2007.

JECKEL-NETO, E. A. Tornar-se velho ou ganhar idade: o envelhecimento biológico revisitado. In: NERI, A. L. (org.). Desenvolvimento e envelhecimento: Perspectivas biológicas, psicológicas e sociológicas. Campinas: Papirus, 2001.

LIMA, M. A. A gestão da experiência de envelhecer em um programa para a terceira idade: a UNATI/UERJ. In: Textos envelhecimento, Rio de Janeiro, v. 2, n. 2, 1999.

MINAYO, M. C. S.; COIMBRA JR, C. E. A.. Introdução: entre a liberdade e a dependência - reflexões sobre o fenômeno social do envelhecimento. In: MINAYO, M. C. S.; COIMBRA JR., C. E. A. (orgs.). Antropologia, saúde e envelhecimento. Rio de Janeiro: FIOCRUZ, 2002.

MORAES, J. F. D.; SOUZA, V. B. A. Fatores associados ao envelhecimento bem-sucedido de idosos socialmente ativos da região metropolitana de Porto Alegre. Revista brasileira de psiquiatria, São Paulo, v. 27, n. 4, p. 302$308,2005$.

MOTTA, A. B. Envelhecimento e sentimento do corpo. In: MINAYO, M. C. S.; COIMBRA JR., C. E. A. (orgs.). Antropologia, saúde e envelhecimento. Rio de Janeiro: FIOCRUZ, 2002. p. 37-50.

PEIXOTO, C. Entre o estigma e a compaixão e os termos classificatórios: velho, velhote, idoso, terceira idade... In: BARROS, M. M. L. (org.). Velhice ou terceira idade? Estudos antropológicos sobre identidade, memória e política. 2. ed. Rio de Janeiro: FGV, 2000. 
PRADO, S. D.; SAYD, J. D. A gerontologia como campo de conhecimento científico: conceito, interesses e projeto político. Revista ciência e saúde coletiva, Rio de Janeiro, v. 11, n. 2, p. 491-501, 2006.

PRINS, B.; MEIJER, I. C. Como os corpos se tornam matéria: entrevista com Judith Butler. Revista Estudos Feministas, Florianópolis, v. 10, n. 1, p. 155-167, 2002.

SÁ, J. L. M. Gerontologia e interdisciplinaridade: fundamentos epistemológicos. In: NERI, A. L.; DEBERT, G. G. (orgs.). Velhice e sociedade. Campinas: Papirus, 1999.

SENNETT, R. O declínio do homem público: as tiranias da intimidade. São Paulo: Cia. das Letras, 1988.

UCHÔA, M. E.; FIRMO, J. O. A.; LIMA-COSTA, M. F. F. Envelhecimento e saúde: experiência e construção cultural. In: MINAYO, M. C. S.; COIMBRA JR., C. E. A. (orgs.). Antropologia, saúde e envelhecimento. Rio de Janeiro: FIOCRUZ, 2002.

VERAS, R. Desafios e conquistas advindas da longevidade da população: o setor saúde e as suas necessárias transformações. In: VERAS, R. (org.). Velhice numa perspectiva de futuro saudável. Rio de Janeiro: UERJ, UnATI, 2001.

WONG, L. L. R.; CARVALHO, J. A. M. O rápido processo de envelhecimento populacional do Brasil: sérios desafios para as políticas públicas. Revista brasileira de estudos de população, Rio de Janeiro, v. 23, n. 1, p. 5-26, 2006.

Recebido em 16/10/2010

Aprovado em 31/10/2011 